\title{
Thin layer chromatography as a simple and quick in- process tool for qualitative and semi-quantitative determination of unentrapped drugs in liposomal formulations
}

\author{
Mukesh KUMAR $1 *$ (D), Swaroop Rameshwarji LAHOTI 2 (D) \\ 1 Department of Pharmaceutics, Y.B Chavan College of Pharmacy, Aurangabad, India. \\ 2 Department of Pharmaceutics, Y.B Chavan College of Pharmacy, Aurangabad, India \\ * Corresponding Author. E-mail: mukeshk32@hotmail.com (M.K.); Tel. +091-956-158 2206.
}

Received: 25 February 2020 / Revised: 04 May 2020 / Accepted: 15 June 2020

\begin{abstract}
Control of free or unentrapped drug is one of the key quality attributes for liposomal drug delivery systems. Conventional methodologies for estimating unentrapped drug in liposomal formulations require prior separation, which are time-consuming and complex. There is a need for a quick in-process analytical technique, which can enable monitoring of drug loading during various stages of product development and manufacturing. A novel simple and rapid TLC procedure was developed for evaluating entrapment efficiency in liposomal formulations. The method is based on differential radial migration of free and entrapped drug on silica gel TLC plates. The method can be employed either as a simple visual qualitative tool in the early screening studies or in a semi-quantitative mode for detection of free and unentrapped drugs. In case of doxorubicin hydrochloride, a deep-red coloured molecule, the method enabled free drug detection up to the levels as low as $2.5 \%$. This method precluded the need of developing the plate further with the mobile phase. The method was used successfully in product development or as an in-process monitoring tool. The method's potential for characterizing entrapment efficiency was evaluated for less intensely coloured or UV absorbing drug candidates such as amphotericin B liposome and curcumin liposome. The preliminary results post derivatization with ninhydrin reagent or visualization under UV light indicated applicability of technique in general for liposomal delivery systems of various other drugs. According to the best of the author's knowledge, there has been no reports on the evaluation of drug entrapment using such TLC based technique so far.
\end{abstract}

KEYWORDS: Liposomal formulation; Unentrapped or free drug; Thin layer chromatography; Supramolecular characterization.

\section{INTRODUCTION}

The concept of using liposomal formulations as site-specific advanced drug carriers have brought drastic improvements in the field of nanomedicines since the first description of liposomes in 1961 [1]. Amongst the various carrier systems, liposomes have generated great interest because of their versatility in terms of size, charge, surface modifications, etc. [2,3]. Liposomes, as the name suggests, are closed vesicles made up of central aqueous core surrounded by spherical phospholipid-based bilayers [4, 5]. The liposomal mode of drug delivery has been successful in the encapsulation of a vast range of drug $[1,5]$. This entrapment can be advantageous as the liposomal carriers protect us from the local effects and site-specific drug toxicity while also protecting normal tissue from damage. Moreover, a more targeted therapy can be exercised in this field. Drugs like doxorubicin hydrochloride, Amphotericin B and many others that otherwise cause toxicity to the host in their free and unentrapped forms are the suitable candidates for liposomal drug delivery [6, 7, 8].

In view of growing significance of liposomal delivery systems, the drug regulatory agencies across the world are encouraging cost effective generic vessions of blockbuster liposomal formulation like AmbisomeTM (Astellas pharma us inc) and DoxilTM (Baxter healthcare corp. US). However, the commercial liposome technology is quite complex involving multistep processes like high pressure homogenisation, drug loading/ size optimization, lyophilization etc. Obtaining pharmaceutical and therapeutic equivalence forms the biggest challenge as even ostensibly alike generic compositions with slight differences in the manufacturing

How to cite this article: Kumar, M., Lahoti, S.R. Thin Layer Chromatography as a cost-effective qualitative and semi-quantitative alternate for determination of unentrapped drugs in liposomal formulations. J Res Pharm. 2020; 24(4): 518-528. 
technology can lead to products with different supramolecular characteristics and therapeutic performance. To enable generic development in a cost effective and timely manner there is a need of rapid inprocess tool for monitoring the drug entrapment efficiency at each step of development and manufacturing.

The characterization of total drug concentration in the liposomal formulation is relatively simpler as it involves breaking of the liposomal vesicles using appropriate solvents or surfactants then the total drug is analyzed by the conventional HPLC. However, quantifying the free and unentrapped drug from the liposomal formulations is a challenging job as an initial separation step is important for the isolation of the unentrapped drug from the remaining liposomal composition. Numerous approaches have been used to determine the amount of unentrapped or entrapped drug in liposomal formulations such as ultrafiltration $[9,10]$, solid-phase extraction [11] capillary electrophoresis [12] cation-exchange resin [13] gel-filtration chromatography, sizeexclusion chromatography [14, 15] ultracentrifugation, dialysis [16] and nanoparticle exclusion chromatography nPEC; [17]. However, each of these operations involves multiple, complex, and timeconsuming steps requiring sophisticated and time consuming equipment and instrumentation. Therefore, these methods are less suitable for in-process characterization of liposome formulations. This paves the path for the development of a simpler method which could enable visual evaluation of bound and free drug in a rapid and cost-effective manner. In the present study we evaluated the feasibility of using thin layer chromatography (TLC) as a possible alternative for qualitative and semi-quantitative determination of unentrapped drug.

Our review of current literature indicated that TLC has predominantly been used coventionally in the characterization of drugs, phospholipids and their degradation products based on separation at molecular level $[18,19,20,21,26$, 27]. There has been a report utilizing TLC for evaluating modification of the different types of phosphatidylcholine liposomal vesicles e.g. multilamellar liposomes (MLV); small unilamellar vesicles (SUV); and reverse phase evaporation vesicles (REV), before and after storage for 15 min in KrebsHenseleit solution [22]. A significant difference in migration pattern was observed in all type of vesicles with the optimized mobile phase. TLC evaluation of liposomes containing a different concentration and type of inositol phosphates derivatives has been studied $[23,24]$. The study observed different migration pattern in the specified derivatives suggesting physico-chemical alterations that eventually change their drug-delivery capacity. In another study, thin-layer gels made with agarose were used to assess changes in the size of multilamellar vesicles that were converted to small unilamellar by sonication [25].

It was interesting to note that no TLC methods were reported for visual characterization of free and entrapped drug specifically in liposomal delivery systems. We observed a potential of utilizing TLC as a semiquantitative tool as the free drug exist differently at supramolecular level. The present study was conducted to characterize the drug entrapment efficiency in liposome formulations based on the differential radial migration of free and entrapped drug on the silica gel TLC plates. This study aims to develop a visual qualitative and a semi-quantitative method to estimate unentrapped drug in common marketed liposomal formulations such as doxorubicin, Amphotericin B and in in-house formulation like curcumin. Doxorubicin has the advantage of being intensely colored which enables direct visualization on the TLC plates. However, there are limitations associated with liposomal drug candidates, which are colorless or weakly-colored, such as Amphotericin B and curcumin. Curcumin was selected as a model candidate for our study as it is soluble in ethanol and extremely hydrophobic, thereby making it a good candidate for liposomal delivery by rapid ethanol injection technique. Its formulation has a light-yellow color, which unfortunately is a bad contrast, unlike doxorubicin liposomes. However, curcumin shows bright fluorescence under UV at $365 \mathrm{~nm}$. Another objective of this study was to explore the suitability of the technique for estimation of drugs, in general, using UV-visualization or derivatization-based detection strategies.

\section{RESULTS}

The results are divided into three sections, according to the three liposomal formulations that were studied.

\subsection{Visual and semi-quantitative evaluation of doxorubicin liposomes}

The estimation of unentrapped drugs was based on the migration pattern of different serial dilutions of doxorubicin $\mathrm{HCl}$ on TLC. Figure 1 shows the amount of Doxorubicin $\mathrm{HCl}$ spotting on the TLC plates as per the sample preparation plan as described in section 5.2.1. When the free drug concentration was increased from 0.00 to $2.00 \mathrm{mg} / \mathrm{ml}$, the intensity in the color of the spot progressively increased as is demonstrated in Figure 1a, D1 to D6. In case of serial dilutions of the entrapped drugs, the spots were comparatively lighter 
and uniform, but bigger than the spots from free drugs (Figure 1b, L1 to L6). This phenomenon is probably due to the faster radial migration of bigger sized liposome in comparison to the significantly smaller size free drug. Study reported previously suggests that size exclusion mode of chromatography is playing a predominant role in this case as different size moieties are migrating radially on the silica gel plate at different rates [25]. However, it should not be ignored that other possible adsorption interactions between free drug, liposomes and surface of silica particles would also play a role. In addition, difference in polarity of the free drug and lipidic vesicles would also contribute in differential migration.

The practical observation convincingly depicts that there is a distinct difference in the migration pattern among free drug (D1 to D6) and entrapped drug (L1 to L6). In case of different ratios of liposomal doxorubicin spiked with free doxorubicin, a set of interesting results were obtained (Figure 1c, M1 to M6). In these, two concentric circles were observed that denoted overlapping zones of the liposomal doxorubicin and the free drug. As the ratio of free drug to entrapped was increased from zero to $2 \mathrm{mg} / \mathrm{ml}$, the color intensity of the free drug (the dark inner circle) increased while the intensity of the liposomal-entrapped drug (outer circle) correspondingly decreased. This direct visual observation successfully distinguished any variables in the free drug proportions that have been spiked in the liposomal dispersion in a qualitative manner. Moreover, it was noted that free drug levels as low as $20 \%$ were detected visually (Figure 1 (c), M2), thereby, indicating the discriminatory efficacy of TLC technique as such.

(a)

Variable concentrations of free Doxorubicin $\mathrm{HC}$

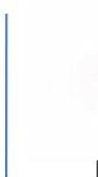

D1

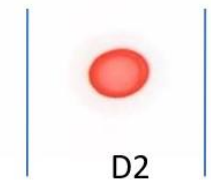

D2

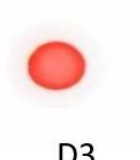

D3

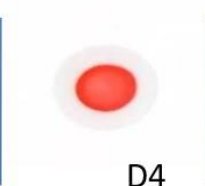

D4

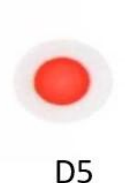

D5

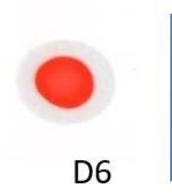

D6

(b) Variable concentrations of liposomal (entrapped) Doxorubicin $\mathrm{HCl}$

$\mid$

L1

(c)
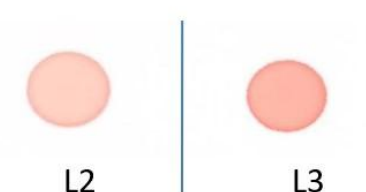

L3

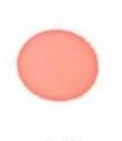

L4

Different ratios of free and entrapped Doxorubicin $\mathrm{HCl}$
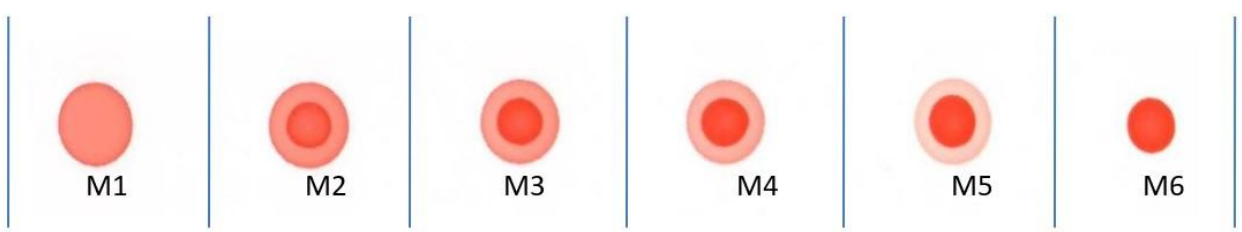

Figure 1. Doxorubicin $\mathrm{HCl}$ spotting on TLC plate as per sample preparations plan specified in Section 1.2.1: (a) Spots D1 - D6 denote increasing order of free drug concentrations (range of 0 to $2 \mathrm{mg} / \mathrm{ml}$ ); (b) Spots L1 L6 denote increasing order of entrapped drug concentrations (range of 0 to $2 \mathrm{mg} / \mathrm{ml}$ ); (c) Spots M1 - M6 denote spiked liposomal sample preparations with an increasing proportion of free drug at the total drug concentration $2 \mathrm{mg} / \mathrm{ml}$.

The next step was to optimize the spotting design in order to evaluate free drug estimation in the practically useful narrow range of $0-10 \%$ of free drugs. The spiked samples prepared as per plan (Table 3) were spotted on the TLC plate. The results of the visual observation of spiked liposome mixtures are presented in Figure 2. As elaborated in figure, increasing proportion of free drugs showed a corresponding increase in color intensity of innier spot even in the narrower range $(0 \%, 2.5 \%, 5.0 \%, 10.0 \%)$. More interestingly, it was observed that the spiked sample containing $2.5 \%$ of free doxorubicin could also be semi-quantitatively differentiated from control ( $0 \%$ free drug) just by visualization. Thus, it can be concluded that TLC was successful in estimating doxorubicin free drugs levels as low as $2.5 \%$. 


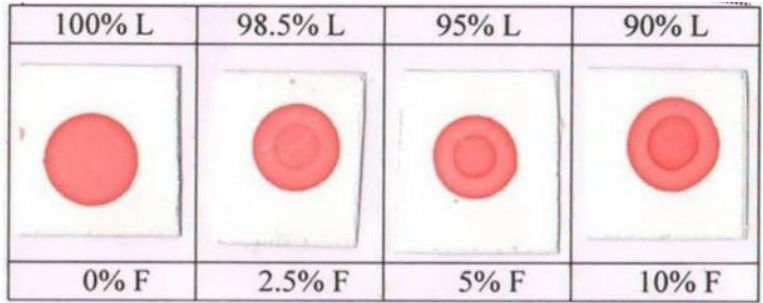

Figure 2. Semi-quantitative evaluation free drug in Doxorubicin $\mathrm{HCl}$ liposome on TLC plate; $\mathrm{L}$ represents entrapped drug (liposomal) whereas F represents free drug. The picture shows spots $0 \% \mathrm{~F}-10 \% \mathrm{~F}(100 \% \mathrm{~L}$ $90 \% \mathrm{~L}$ ) denoting increasing order of free drug concentrations in the narrow practical range (total drug conc. of $2 \mathrm{mg} / \mathrm{ml}$ ).

\subsection{Validation of semi-quantitative accuracy of results}

The validity of the TLC based concept was estabilished by comparative evaluation of percentage free drug in liposomal samples subjected to accelerated drug release by sonication. The drug release observed by TLC technique was compared against HPLC based quantitation. The data as shown in table 1 suggested that the free drug results at different sonication levels by semiquantitative TLC technique were in close agreement with HPLC methodology. Hence it can act as a quick in-process tool to estimate free drug levels during the encapsulation processing.

Table 1. Comparative estimation of percentage free drug (HPLC vs TLC based evaluation)

\begin{tabular}{cccc}
\hline $\begin{array}{c}\text { Sample } \\
\text { No. }\end{array}$ & $\begin{array}{c}\text { Sonication time } \\
\text { (Min) }\end{array}$ & $\begin{array}{c}\text { Results by HPLC } \\
(\mathbf{\%})\end{array}$ & $\begin{array}{c}\text { Results by } \\
\text { TLC (\%) }\end{array}$ \\
\hline $\mathbf{1}$ & 0 & $0.9+0.2$ & $<2.5 \%$ \\
$\mathbf{2}$ & 10 & $3.7+0.4$ & $2.5-5.0 \%$ \\
$\mathbf{3}$ & 20 & $6.2+0.4$ & $5.0-7.5 \%$ \\
$\mathbf{4}$ & 30 & $9.1+0.3$ & $7.5-10 \%$ \\
\hline \multirow{2}{*}{ *Mean \pm standard deviation $(\mathrm{n}=3)$} & &
\end{tabular}

\subsection{Feasibility of drug loading evaluation of amphotericin B liposome}

Figure 3 depicts the TLC evaluation of different lots/makes of Amphotericin B Liposome as tested under the UV light at $254 \mathrm{~nm}$. It was observed that in the first batch that was evaluated, the innovator product spot (INV) was quite uniform in comparison to others (in-house and market products). Within the market products, M1 showed a distinct inner dark spot in particular, suggesting the presence significant free drug in that sample. Other products, such as M2 and M3 showed a pattern closer to the innovator. The in-house developmental batches ( $\mathrm{H} 1$ and $\mathrm{H} 2$ ) showed a tiny spot of free drug in the middle. Thus, there was a clear distinction between almost all the samples.

In order to evaluate the source of the inner circle and to improvise any discrimination, the new sets were evaluated post-derivatization with ninhydrin reagent. Figure 3 (b) and (c) show migration patterns of different concentrations of entrapped and free drug respectively. The entrapped drug appeared as greyish bigger circles, whereas the free drug exhibited light to dark brownish smaller circles. In both cases, there was an increase in the intensity of the color with the increase in the sample concentration. Figure 3 (d) depicts the migration pattern of free drug spiked with different proportion of entrapped drug keeping the total drug concentration constant $(2 \mathrm{mg} / \mathrm{ml})$. It was observed that the circles started becoming lighter and bigger with an increasing proportion of entrapped drug (T1-T6) as the inner spot was found to be due to free drug. The sample containing $20 \%$ free drug (T5) was visually distinguishable from control (T6). Therefore, it can be inferred that TLC was successfully able to visually and semi-quantitatively evaluate free Amphotericin B drug.

\subsection{Feasibility of Drug Loading Evaluation of Curcumin Liposome}

Similarly, Curcumin liposomes were evaluated under the UV light at $365 \mathrm{~nm}$ as maximum clarity was observed in this wavelength. As the marketed control samples for Curcumin were not available, the testing plan was different from the previous drug formulations. The preliminary formulation prepared in-house containing about $99.5 \%$ of the entrapped drug was taken as controls. Figure 4 shows the migration pattern of increasing concentration of free drugs ( $\mathrm{C} 1$ to $\mathrm{C} 6)$. The spots were non-homogenous and brighter in the center. 
These were light bluish to yellow in color and visually showed an increase in color intensity with increase in the free drug concentration. The visual pattern for the different dilutions of liposomal formulation was also quite distinct (E1 to E6). The color of curcumin was almost invisible in the liposomal entrapped dilutions at different concentrations. This observation was considered critical, especially for the semi- quantitative estimation of the free drug as it enabled visual evaluation of the free drug in the liposomal dispersion. Interestingly, a different spotting pattern was observed in case of liposomal drug spiked with different percentage of free drugs ranging from 5 to $100 \%$ of free drug (J1 to J6). The spots were uniform having similar size as liposomally entrapped drug and showing an increase in the color intensity with increasing percentage of free drug. This observation was in contrast to the observations made for spiked doxorubicin liposome wherein concentric circle was observed representing different zones of free and entrapped drug. The observed phenomena could be due to the uniform adsorption of free drug molecules to the liposomal surface due to highly hydrophobic nature of the drug. However, the spotting pattern clearly distinguishes free drug level up to $5 \%$ in the spiked liposomes. To the best of the author's knowledge, so far there is no report published in the literature indicating the use of this kind of separation technique for quick quantification of free drug in liposomal delivery. The utility of our study is supported by the studies of Yamamoto et al. who also determined the free drug/entrapment efficiency in doxorubicin liposomal delivery using alternative rapid nanoparticle exclusion HPLC (nPEC) technique [17].

(a) Comparative TLC evaluation of Different Formulations in UV light

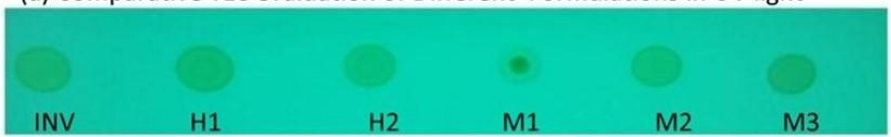

(b) Amphotericin B Entrpped (Liposomal) Drug in increasing order of Conc.

A2

A3

A4

A5

A6

(c) Amphoericin B Free Drug Dispersion in increasing order of Conc.

F1 F2 $\quad F 3 \quad F 4 \quad F 5$

(d) Free Amphotericin B Spiked with Increasing Proportion of Entrapped Drug

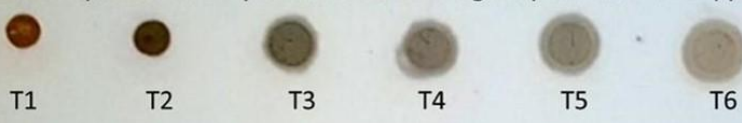

Figure 3. Amphotericin B spotting on TLC plate; (a) Spotting of different finished product samples as per sample preparations plan specified in Section 1.2.2; INV denotes innovator product, H1 and H2 denote inhouse developmental batches whereas M1, M2, M3 denote marketed products of different brands, (b) spots A1-A6 denote increasing order of entrapped drug concentrations (range of 0 to $2 \mathrm{mg} / \mathrm{ml}$ ); (c) spots F1-F6 denote increasing order of free drug concentrations (range of 0 to $2 \mathrm{mg} / \mathrm{ml}$ ); (c) spots T1 - T6 denote spiked free drug sample preparations with an increasing proportion of entrapped drug at the total drug concentration of $2 \mathrm{mg} / \mathrm{ml}$.

\section{DISCUSSION}

The aim of our study was to develop and validate TLC as a qualitative and semi-quantitative in-process tool for the estimation of unentrapped drugs in common liposomal formulations of Doxorubicin and Amphotericin B. Along with this, the method was also tested for Curcumin drug formulation. Among these three drug formulations, TLC was found to be the most suitable method for doxorubicin liposomes with respect to rapidity and sensitivity. Doxorubicin is an easy visual marker compared to Amphotericin and Curcumin, where UV lights or derivatization are required for detection. In our study, TLC technique was found to be more sensitive to detect free drug levels as low as $2.5 \%$ in the doxorubicin liposomal formulation and $5 \%$ for Curcumin liposome. However, in case of Amphotericin B, the minimum level of detection was higher $(20 \%)$ compared to the other two. The overall data shows that the detection of the free drugs is dependent on a various aspects such as the type of drug, intraction with stationary silica phase, liposome size, the radial migration rate, liposomal $\mathrm{pH}$, polarity of intracting components and most importantly the mode of visualization $[22,23,25,28]$. 


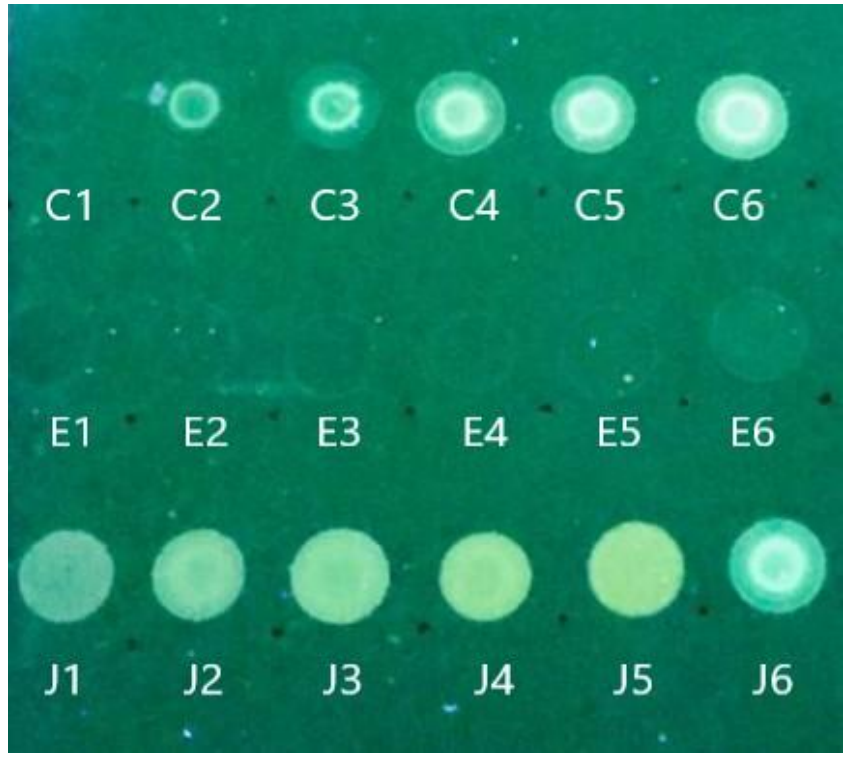

Figure 4. Curcumin spotting on TLC plate: (a) Spotting of free drug samples as per sample preparation plans specified in Section 1.2.3; C1 to C6 denote free drug concentrations (range of 0.5 to $10 \mu \mathrm{g} / \mathrm{ml}$ ) (b) Spots E1 E6 denote increasing order of entrapped drug concentrations (range of 0.5 to $10 \mu \mathrm{g} / \mathrm{ml}$ ) and (c) Spots J1 to J6 denote spiked free drug sample preparations with an increasing proportion of free drug (range 5 to 100 $\%$ ) at the total drug concentration $10 \mu \mathrm{g} / \mathrm{ml}$.

It was observed that this method was able to determine the presence of free drug within a few seconds after spotting in case of doxorubicin liposome. Moreover, it is visually attractive, rapid and cost effective as it does not require any sophisticated instrumentation or equipment. The present technique has industrial relavance for products like Doxorubicin liposomes wherein the generic manufacturing involves mutiplestep processses like formation of empty liposome, buffer exchange by dialysis, active drug loading, sterile filtration and filling. There is a need of inprocess tool that can indicate the extent of activ drug loading quickly enabling the formulator to take appropriate action and move to the next step. The conventional separation/HPLC methodology may take 3-5 hrs time time for each tweaking in free drug optimization step resulting in significant extension of processing time. Such tool if refined and validated appropriately can result in significant saving of overall processing time resulting in higher productivity.

In addition, the technique allows the qualitative comparison of different brands of the same product on the same plate. Thus, this method has a wide scope in its practical application and can be used as a powerful tool capable of regulating drugs on a routine basis. There has been a report according to which the Indian government suspended the manufacturing licenses of the ten drug companies manufacturing liposomal drugs due to quality issues in the drug formulations [30]. The present method provides a quick tool enabling such kind of monitoring at a broader national level.

The proposed technique will also be helpful in boosting research in academia wherein it could facilitate early stage screening of any promising candidate without the need of complicated analytical infrastructure. The simplicity of the technique would facilitate quality research in third world academia around the world.

\section{CONCLUSION AND RECOMMENDATIONS FOR THE FUTURE}

A rapid TLC based method has been developed to estimate the presence of unentrapped drugs in liposomal formulations visually as well as semi-quantitatively. So far, there is no method reported for the estimation of liposomal drug loading using such simple technique. This approach serves best for practical purposes by using it as an in-process monitoring tool during formulation and development of liposome compositions, in particular. This method can be applied to every stage of liposome preparation process in order to monitor the possible errors of the preparation procedure and ultimately to analyze the level of free drug content of the final liposomal composition.

In our study we have used this technique for characterizing liposomal drug delivery. However, it has a lot of future scope for supramolecular characterization of other forms of nanomedicines like iron complexes, polymeric micelles (Nanoxel) and albumin-coated nanoparticles (Abraxane) [31]. As a step further, there ia scope for refinement of technique by enabling densitometric quantification. Any additional efforts to separate 
the free drug from the entrapped drug through the use of appropriate mobile and stationary phase would help in making the technique more sensitive, quantitative and universal. As this technique is still in its infancy, there is always a room for any kind of improvement in the technique. Further research in this area by the scientific community may open up a new era in the field of nano-characterization of complex pharmaceuticals.

\section{MATERIALS AND METHODS}

\subsection{Chemicals and chromatographic system}

Doxorubicin hydrochloride USP (Synbias, Ukrain), Amphotericin B USP (Xellia, Denmark), Curcumin ( $\geq 94 \%$ curcuminoid content, Merck, India) lipoid S 100 (Lipoids GmBH), cholesterol (Dishman NZ), absolute ethanol USP (Brompton Canada), histidine (Merck, Germany), dextrose (Merck, India) and sodium chloride USP (Merck Germany) were procured from the respective vendors. Ninhydrin agent and dimethyl sulfoxide (DMSO) were procured from Sigma-Aldrich. The innovator liposomal formulations under the brand name

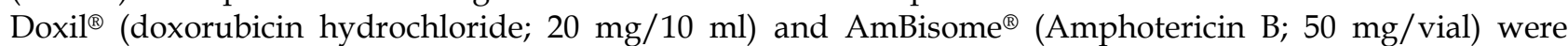
obtained as gift samples from Wockhardt Ltd. The domestic Amphotericin B liposomal formulations from three brands having a composition identical to AmBisome ${ }^{\circledR}$ were procured from the local market. Chromatographic plates for TLC analysis of size $10 \times 10 \mathrm{~cm}$, cut from $20 \times 20 \mathrm{~cm}$ (E. Merck, Germany) was prepared. The aluminum (Al) plates precoated with silica gel-60F254 (Art. 1.05554) were utilized.

\subsection{Sample preparation for TLC evaluation of drugs}

For the preparation of serial dilutions of all the liposomal drug products to be used in TLC spotting, all the final dilutions were prepared in $2 \mathrm{ml}$ centrifuge tubes using calibrated micropipettes.

\subsubsection{Preparation of Doxil ${ }^{\circledR}$ (Doxorubicin) Liposomal product}

Two stock solutions representing free and entrapped drug, each with $2 \mathrm{mg} / \mathrm{ml}$ concentration were used for making the various dilutions of liposomal formulations. The commercial Doxil ${ }^{\circledR}$ formulation has been considered to reach $100 \%$ entrapped drug level as studies conducted previously employing size exclusion and HPLC methodology of the Doxil ${ }^{\circledR}$ indicated that the actual amount of unentrapped drug was below 0.5\% [32]. Therefore, for practical purposes, the marketed product was used as a reference to demonstrate $100 \%$ entrapment efficiency in our study. The free drug stock solution corresponding to liposomal product was prepared at a concentration of $2 \mathrm{mg} / \mathrm{ml}$ in $0.01 \mathrm{M}$ histidine buffer $(\mathrm{pH} 6.5)$ as this buffer is also used in liposomal formulations. Six serial dilutions were made in concentrations ranging from 0 to $2 \mathrm{mg} / \mathrm{ml}$ with an interval of $0.4 \mathrm{mg} / \mathrm{ml}$ for both doxorubicin $\mathrm{HCl}$ free solution (labeled as D1- $0 \mathrm{mg} / \mathrm{ml}$ to D6- $2 \mathrm{mg} / \mathrm{ml}$ ) and entrapped liposomal dispersion (labeled as L1-0 mg/ml to L6- $2 \mathrm{mg} / \mathrm{ml}$ ). Six solutions were prepared where liposomal dispersions were spiked with free drug solutions, maintaining the same concentration of $2 \mathrm{mg} / \mathrm{ml}$ and labeled from lowest level (labeled as M1) with no free drugs and $2 \mathrm{mg} / \mathrm{ml}$ of entrapped drug concentration to highest level (labeled as M6) with $2 \mathrm{mg} / \mathrm{ml}$ of free drugs and no entrapped drugs. The entrapment percent varied from $0 \%$ in M1 to $100 \%$ in M6. The overall dilution plan is shown in Table 2.

Table 2. Doxorubicine HCL sample preparations for TLC plate spotting (Diluent: Histidine buffer 0.01M; $\mathrm{pH}$ 6.5).

\begin{tabular}{cccccccc}
\hline \multicolumn{2}{c}{ Free drug Solution } & \multicolumn{2}{c}{$\begin{array}{c}\text { Liposomal Dispersion (Entrapped } \\
\text { Drug) }\end{array}$} & $\begin{array}{c}\text { Liposomal Dispersion spiked with } \\
\text { free drug solution at a total drug } \\
\text { concentration of 2 mg/ml }\end{array}$ \\
\hline $\begin{array}{c}\text { Sample } \\
\text { code }\end{array}$ & $\begin{array}{c}\text { Free Drug } \\
\text { Conc. } \\
\text { (mg/ml) }\end{array}$ & $\begin{array}{c}\text { Sample } \\
\text { code }\end{array}$ & $\begin{array}{c}\text { Entrapped Drug } \\
\text { Conc. }(\mathbf{m g} / \mathbf{m l})\end{array}$ & $\begin{array}{c}\text { Sample } \\
\text { Code }\end{array}$ & $\begin{array}{c}\text { Free Drug } \\
\text { Conc. } \\
\text { (mg/ml) }\end{array}$ & $\begin{array}{c}\text { Entrapped } \\
\text { Drug Conc. } \\
\text { (mg/ml) }\end{array}$ & $\begin{array}{c}\text { Free } \\
\text { Drug }\end{array}$ \\
\hline D1 & 0.00 & L1 & 0.00 & M1 & 0.00 & 2.00 & 0.0 \\
D2 & 0.40 & L2 & 0.40 & M2 & 0.40 & 1.60 & 20.0 \\
D3 & 0.80 & L3 & 0.80 & M3 & 0.80 & 1.20 & 40.0 \\
D4 & 1.20 & L4 & 1.20 & M4 & 1.20 & 0.80 & 60.0 \\
D5 & 1.60 & L5 & 1.60 & M5 & 1.60 & 0.40 & 80.0 \\
D6 & 2.00 & L6 & 2.00 & M6 & 2.00 & 0.00 & 100.0 \\
\hline
\end{tabular}

To further understand the sensitivity of Doxorubicin, further dilutions of $0 \%, 2.5 \%, 5.0 \%$ and $10.0 \%$ free drug were prepared in analogues manner and spotted on the TLC plate. The study was performed in order to 
narrow the range from $0-100 \%$ to 0 to $10 \%$. The set of spiked samples with corresponding dilutions has been depicted in Table 3.

Table 3. Doxorubicine $\mathrm{HCl}$ spiked sample preparations for the evaluation of method sensitivity.

\begin{tabular}{cccc}
\hline \multicolumn{4}{c}{ Liposomal Dispersion spiked with free drug solution at a total drug concentration of $\mathbf{2} \mathbf{~ m g} / \mathbf{m l}$} \\
\hline Sample code & Free Drug Conc. $(\mathbf{m g} / \mathbf{m l})$ & Entrapped Drug Conc. $(\mathbf{m g} / \mathbf{m l})$ & \% Free Drug \\
\hline $\mathbf{0} \% \mathrm{~F}(\mathbf{1 0 0} \% \mathrm{~L})$ & 0.00 & 2.00 & 0.0 \\
$\mathbf{2 . 5} \% \mathrm{~F}(\mathbf{9 7 . 5} \% \mathrm{~L})$ & 0.05 & 1.95 & 2.5 \\
$\mathbf{5 . 0} \% \mathrm{~F}(\mathbf{9 5} \% \mathrm{~L})$ & 0.10 & 1.90 & 5.0 \\
$\mathbf{1 0} \% \mathrm{~F}(\mathbf{9 0} \% \mathrm{~L})$ & 0.20 & 1.80 & 10.0 \\
\hline
\end{tabular}

\subsubsection{Validation of semi-quantitative accuracy for doxorubicin liposome}

The suitability of the technique was verified by intentionally extracting the free drug from marketed liposomal product at different free drug levels. The drug was released from the liposomal sample by sonicating the samples at $37^{\circ} \mathrm{C}$ under low frequency for a time interval ranging from 2 to 30 minutes. The extent of free drug in each sample was quantified by reported size exclusion and HPLC methodology in triplicate [32]. The same samples were also evaluated by TLC for the semiquatitative evaluation of free drug against the spiked liposomal standards. The observed HPLC results were compared against TLC based values in order to ascertain the semi-quantitative accuracy of the results.

\subsubsection{Preparation of AmBisome ${ }^{\circledR}$ (Amphotericin B) liposomal product}

A preliminary study evaluating Amphotericin B liposomes showed that Amphotericin B produces feebly yellow colored spot on the TLC plate. Therefore, in this case, the visual observation was ineffective for monitoring any form drug on the TLC plates. However, this was possible under UV light or using ninhydrinbased derivatization. The first batch of samples included one lot of the innovator (INV), two batches of inhouse samples ( $\mathrm{H} 1$ and $\mathrm{H} 2$ ) and three generic brands from the market (M1 to $\mathrm{M} 3$ ) that were evaluated directly from the TLC plate under the UV light $(254 \mathrm{~nm})$. The vials of each of the lyophilized product samples were reconstituted in $5 \%$ dextrose to a final drug concentration of $2 \mathrm{mg} / \mathrm{ml}$. Similar to doxorubicin $\mathrm{HCl}$ formulation, the commercial AmBisome ${ }^{\circledR}$ formulation was considered as the $100 \%$ entrapped drug level for our study. The stock dispersions representing both, free and entrapped drug at the concentration each of $2 \mathrm{mg} / \mathrm{ml}$ in $5 \%$ dextrose were used for making further dilutions. As Amphotericin B has limited solubility in water, therefore, it was first solubilized in DMSO $(50 \mathrm{mg} / \mathrm{ml})$ and then diluted subsequently in $5 \%$ dextrose to get a final free drug concentration of $2 \mathrm{mg} / \mathrm{ml}$, which existed as a colloidal dispersion. Similar to the previous Doxorubicin sample preparation (Section 5.2.1), six serial dilutions were made in concentrations ranging from 0 to $2 \mathrm{mg} / \mathrm{ml}$ with an interval of $0.4 \mathrm{mg} / \mathrm{ml}$ for both Amphotericin B solutions in free form and entrapped form. In case of entrapped liposomal dispersions, A1 had no entrapped drugs, whereas A6 had $2 \mathrm{mg} / \mathrm{ml}$ of the entrapped drug. F1 to F6 ranged from 0 to $2 \mathrm{mg} / \mathrm{ml}$ of free drug only. Six solutions were also prepared where liposomal dispersions were spiked with free drug solutions, maintaining the same concentration of $2 \mathrm{mg} / \mathrm{ml}$. The free drug percent varied from $100 \%$ in $\mathrm{T} 1$ to $0 \%$ in T6 as explained in Table 4.

Table 4. Serial dilutions of Amphotericin B liposomal dispersions spiked with free drug solution for TLC plate spotting.

\begin{tabular}{|c|c|c|c|c|c|c|c|}
\hline \multicolumn{2}{|c|}{$\begin{array}{l}\text { Liposomal Dispersion } \\
\text { (Entrapped Drug) }\end{array}$} & \multicolumn{2}{|c|}{ Free Drug Dispersion } & \multicolumn{4}{|c|}{$\begin{array}{c}\text { Liposomal Dispersion Spiked with Free } \\
\text { Drug Dispersion at a Total Drug Conc. of } 2 \\
\mathrm{mg} / \mathrm{ml}\end{array}$} \\
\hline $\begin{array}{l}\text { Sample } \\
\text { Code }\end{array}$ & $\begin{array}{l}\text { Liposomal } \\
\text { Drug Conc. } \\
(\mathrm{mg} / \mathrm{ml})\end{array}$ & Sample Code & $\begin{array}{l}\text { Free Drug } \\
\text { Conc. } \\
(\mathrm{mg} / \mathrm{ml})\end{array}$ & $\begin{array}{l}\text { Sample } \\
\text { Code }\end{array}$ & $\begin{array}{l}\text { Free } \\
\text { Drug } \\
\text { Conc. } \\
(\mathrm{mg} / \mathrm{ml})\end{array}$ & $\begin{array}{l}\text { Entrapped } \\
\text { Drug } \\
\text { Conc. } \\
(\mathrm{mg} / \mathrm{ml})\end{array}$ & $\begin{array}{l}\% \text { Free } \\
\text { Drug }\end{array}$ \\
\hline A1 & 0.00 & F1 & 0.00 & T1 & 2.00 & 0.00 & 100.0 \\
\hline A2 & 0.40 & $\mathrm{~F} 2$ & 0.40 & $\mathrm{~T} 2$ & 1.60 & 0.40 & 80.0 \\
\hline A3 & 0.80 & F3 & 0.80 & $\mathrm{~T} 3$ & 1.20 & 0.80 & 60.0 \\
\hline A4 & 1.20 & $\mathrm{~F} 4$ & 1.20 & $\mathrm{~T} 4$ & 0.80 & 1.20 & 40.0 \\
\hline A5 & 1.60 & F5 & 1.60 & T5 & 0.40 & 1.60 & 20.0 \\
\hline A6 & 2.00 & F6 & 2.00 & T6 & 0.00 & 2.00 & 0.0 \\
\hline
\end{tabular}




\subsubsection{Preparation of cucurmin liposomal product}

As there was no commercial liposomal product available in the market, curcumin liposome formulations were prepared in the lab using the rapid ethanolic lipid injection technique. In this process, an alcoholic lipid concentrate comprising of $2.5 \mathrm{mg} / \mathrm{ml}$ of curcumin and $50 \mathrm{mg} / \mathrm{ml}$ of Lipoid S-100 (soya lecithin) and $12.5 \mathrm{mg} / \mathrm{ml}$ of cholesterol was prepared in absolute ethanol. The solution required gentle heating in the water bath at about $60-70{ }^{\circ} \mathrm{C}$ to result in a clear solution. After this, $1 \mathrm{ml}$ of the lipid concentrate was injected rapidly through a $29 \mathrm{G}$ needle into $9 \mathrm{ml}$ of water and stored in a $20 \mathrm{ml}$ glass vial. The mixture was shaken vigorously to result in a liposomal dispersion with final drug concentration of $0.25 \mathrm{mg} / \mathrm{ml}$. The resultant semi translucent yellow liposomal dispersion comprised of free as well as entrapped drugs. Since, curcumin is highly hydrophobic, it remained associated with the lipid bilayer. The free drug in the liposomes was analyzed by ultrafiltration (UF) using Amicon Ultra-2 Centrifugal Filter Unit, 10 KD. The liposomal dispersion was centrifuged at $10000 \mathrm{rpm}$ for 10 minutes and then the free drug content in the ultrafiltrate was analyzed using HPLC as reported in [33]. The mean entrapment efficiency in this case was found to be $99.6 \pm 0.3 \%$. Since, the free drug content was found to be less than $0.5 \%$, therefore, the dispersion was considered to be fully entrapped for practical reasons. In this study, the liposomal dispersion was diluted with the water to the form a primary stock solution of the entrapped drug with concentration of $10 \mu \mathrm{g} / \mathrm{ml}$. After this, a methanolic solution of curcumin $(100 \mu \mathrm{g} / \mathrm{ml})$ was diluted with water to get a solution of $10 \mu \mathrm{g} / \mathrm{ml}$ concentration, which forms the primary stock solution of the free drug. These two stock solutions were used in making various dilutions representing different fractions of free drugs (from C1 with $0.5 \mu \mathrm{g} / \mathrm{ml}$ and C6 with $10 \mu \mathrm{g} / \mathrm{ml}$ of free drugs), entrapped drugs (from E1 with $0.5 \mu \mathrm{g} / \mathrm{ml}$ to E6 with $10 \mu \mathrm{g} / \mathrm{ml}$ of entrapped drugs and six serial solutions (J1 to J6) of the entrapped drug spiked with free drug as shown in Table 5.

Table 5. Serial dilutions of Curcumin liposomal dispersions spiked with free drug solution for TLC plate spotting.

\begin{tabular}{|c|c|c|c|c|c|c|c|}
\hline \multicolumn{2}{|c|}{ Free Drug Solution } & \multicolumn{2}{|c|}{ Liposomal Dispersion } & \multicolumn{4}{|c|}{$\begin{array}{l}\text { Liposomal Dispersion spiked with free drug } \\
\text { (total drug }: 10 \mu \mathrm{g} / \mathrm{ml} \text { ) }\end{array}$} \\
\hline $\begin{array}{l}\text { Sample } \\
\text { code }\end{array}$ & $\begin{array}{c}\text { Free Drug } \\
\text { Conc } \\
(\mu \mathrm{g} / \mathrm{ml})\end{array}$ & Sample code & $\begin{array}{c}\text { Entrapped } \\
\text { Drug Conc } \\
(\mu \mathrm{g} / \mathrm{ml})\end{array}$ & Sample code & $\begin{array}{l}\text { Free } \\
\text { Drug } \\
\text { Conc } \\
(\mu \mathrm{g} / \mathrm{ml})\end{array}$ & $\begin{array}{c}\text { Entrapped } \\
\text { Drug } \\
\text { Conc } \\
(\mu \mathrm{g} / \mathrm{ml}) \\
\end{array}$ & $\begin{array}{l}\text { \% Free } \\
\text { Drug }\end{array}$ \\
\hline $\mathrm{C1}$ & 0.5 & E1 & 0.5 & J1 & 0.5 & 9.5 & 5 \\
\hline $\mathrm{C} 2$ & 2.0 & E2 & 2.0 & $\mathrm{~J} 2$ & 2.0 & 8.0 & 20 \\
\hline $\mathrm{C} 3$ & 4.0 & E3 & 4.0 & $\mathrm{~J} 3$ & 4.0 & 6.0 & 40 \\
\hline $\mathrm{C} 4$ & 6.0 & $\mathrm{E} 4$ & 6.0 & $\mathrm{~J} 4$ & 6.0 & 4.0 & 60 \\
\hline C5 & 8.0 & E5 & 8.0 & J5 & 8.0 & 2.0 & 80 \\
\hline C6 & 10.0 & E6 & 10.0 & J6 & 10.0 & 0.0 & 100 \\
\hline
\end{tabular}

\subsection{Sample application and detection on TLC plates}

Samples with different concentrations of free, entrapped drug and corresponding mixtures were applied directly as a drop on the aluminum chromatographic plates that have been precoated with silica gel. To avoid any manual error, a drop of $10 \mu \mathrm{L}$ of test solution was placed carefully and gradually on the TLC plate using a $50 \mu \mathrm{L}$ micropipette. It was ensured that the samples were applied uniformly as a single drop so as to allow the effective differential migration of free and bound drug in a radial direction. The uniformity in the manual application technique was found to be critical for qualitative visualization and semi-quantitative comparison. As the technique relies simply on differential radial migration from the sample applied as a drop, no mobile phase was used to develop the plates. Doxorubicin samples were evaluated visually directly after application, whereas, Amphotericin B and Curcumin were detected either under the UV light or after post ninhydrin agent derivatization. 
Acknowledgements: The authors are grateful to Dr. Jayrajsinh Sarvaiya, Asst. Professor and Abhishek Shrivastava (M. Pharm, second year), both from the Institute of Research \& Development, Gandhinagar, Gujarat, India for supporting experimentation of the article. This study was sponsored by Wockhardt Research Centre, D-4, MIDC Chikalthana, Aurangabad 431006, India.

Author contributions: Concept - M.K., S.R.L.; Design - M.K.; Supervision - M.K.; Resources - M.K.; Materials - M.K.; Data Collection and/or Processing - M.K.; Analysis and/or Interpretation - M.K., S.R.L.; Literature Search - M.K.; Writing - M.K.; Critical Reviews - M.K., S.R.L.

Conflict of interest statement: The authors declared no conflict of interest.

\section{REFERENCES}

[1] Bulbake U, Doppalapudi S, Kommineni N, Khan W. Liposomal formulations in clinical use: an updated review. Pharmaceutics. 2017; 9(2): 12. [CrossRef]

[2] Chang HI, Yeh MK. Clinical development of liposome-based drugs: formulation, characterization, and therapeutic efficacy. Int J Nanomedicine. 2012; 7: 49-60. [CrossRef]

[3] Kapoor M, Lee SL, Tyner KM. Liposomal drug product development and quality: current US experience and perspective. The AAPS Journal. 2017; 19(3): 632-641. [CrossRef]

[4] Allen TM. Liposomal drug formulations. Drugs. 1998; 56(5): 747-756. [CrossRef]

[5] Panwar P, Pandey B, Lakhera PC, Singh KP. Preparation, characterization, and in vitro release study of albendazoleencapsulated nanosize liposomes. Int J Nanomedicine. 2010; 5: 101-108. [CrossRef]

[6] Gabizon AA. Pegylated liposomal doxorubicin: metamorphosis of an old drug into a new form of chemotherapy. Can. Invest. 2001; 19(4): 424-436. [CrossRef]

[7] Ali MZ, Foad AS, Zarrabi A, Reza TM. Liposomal doxorubicin delivery systems: effects of formulation and processing parameters on drug loading and release behavior. Current Drug Deliv. 2016; 13(7): 1065-1070.

[8] Szebeni J, Fülöp T, Dézsi L, Metselaar B, Storm G. Liposomal doxorubicin: the good, the bad and the not-so-ugly. J Drug Target. 2016; 24(9): 765-767. [CrossRef]

[9] Chen D, Cole DL, Srivatsa GS. Determination of free and encapsulated oligonucleotides in liposome formulated drug product. J Pharmaceut Biomed. 2000; 22(5): 791-801. [CrossRef]

[10] Mayer LD, Onge GS. Determination of free and liposome-associated doxorubicin and vincristine levels in plasma under equilibrium conditions employing ultrafiltration techniques. Anal Biochem. 1995; 232(2): 149-157. [CrossRef]

[11] Thies RL, Cowens DW, Cullis PR, Bally MB, Mayer LD. Method for rapid separation of liposome-associated doxorubicin from free doxorubicin in plasma. Anal Biochem. 1990; 188(1): 65-71. [CrossRef]

[12] Griese N, Blaschke G, Boos J, Hempel G. Determination of free and liposome-associated daunorubicin and daunorubicinol in plasma by capillary electrophoresis. J Chromatogr A. 2002; 979(1-2): 379-388. [CrossRef]

[13] Druckmann S, Gabizon A, Barenholz Y. Separation of liposome-associated doxorubicin from non-liposomeassociated doxorubicin in human plasma: implications for pharmacokinetic studies. Biochim Biophys Acta. 1989; 980(3): 381-384. [CrossRef]

[14] Edwards KA, Baeumner AJ. Analysis of liposomes. Talanta. 2006; 68(5): 1432-1441. [CrossRef]

[15] Gomez-Hens A, Fernandez-Romero JM. Analytical methods for the control of liposomal delivery systems. Trend Anal Chem. 2006; 25(2): 167-178. [CrossRef]

[16] Dipali SR, Kulkarni SB, Betagiri GV. Comparative study of separation of non- encapsulated drug from unilamellar liposomes by various methods. J Pharm Pharmacol. 1996; 48(11): 1112-1115. [CrossRef]

[17] Yamamoto E, Miyazaki S, Aoyama C, Kato M. A simple and rapid measurement method of encapsulation efficiency of doxorubicin loaded liposomes by direct injection of the liposomal suspension to liquid chromatography. Int $\mathrm{J}$ Pharm. 2018; 536(1): 21-28. [CrossRef]

[18] Dhanesar SC, Peeler TR, Engel BS. Evaluation of phospholipids in liposomes by HPTLC. J Planar Chromat. 1992; 5(1): 45-49.

[19] Holzer M, Burghardt A, Schubert R. Quantitative high-performance thin-layer chromatography determination of common liposome components and critical parameters influencing the analysis results. J Liposome Res. 2010; 20(2): 124-133. [CrossRef] 
[20] Hatziantoniou S, Demetzos C. Method of simultaneous analysis of liposome components using HPTLC/FID. In: D’Souza (Eds). Liposomes. Humana Press, New York, NY, USA, 2010, pp. 363-368. [CrossRef]

[21] Hatziantoniou S, Demetzos C. Method of simultaneous analysis of liposome components using HPTLC/FID. In: D’Souza (Eds). Liposomes. Humana Press, New York, NY, USA, 2017, pp. 49-54 [CrossRef]

[22] Brailoiu E, Saila L, Huhurez G, Costuleanu M, Filipeanu CM, Slatineanu S, Cotrutz C, Branisteanu DD. TLC - A rapid method for liposome characterization. BMC. 1994; 8(4): 193-195. [CrossRef]

[23] Brailoiu E, Huhurez G, Slatineanu S, Filipeanu CM, Costuleanu M, Branisteanu DD. TLC characterization of liposomes containing D- myo- inositol derivatives. BMC. 1995; 9(4): 175-178. [CrossRef]

[24] Brailoiu E, Beschea C, Brailoiu C, Costuleanu A, Filipeanu CM, Costuleanu M, Fallgrens B, Branisteanu DD. TLC Characterization of Small Unilamellar Liposomes Containing D- myo- Inositol Derivatives. BMC. 1996; 10(5): 233236. [CrossRef]

[25] Van Renswoude AJ, Blumenthal R, Weinstein JN. Thin-layer chromatography with agarose gels: A quick, simple method for evaluating liposome size. Biochim Biophys Acta. 1980; 595(1): 151-156. [CrossRef]

[26] Nicoletti M. HPTLC fingerprint: a modern approach for the analytical determination of botanicals. Rev Bras Farmacogn. 2011; 21(5): 818-823. [CrossRef]

[27] Ansari MJ, Ahmad S, Kohli K, Ali J, Khar RK. Stability-indicating HPTLC determination of curcumin in bulk drug and pharmaceutical formulations. J PharmBiomed. 2005; 39(1-2): 132-138. [CrossRef]

[28] Fritze A, Hens F, Kimpfler A, Schubert R, Peschka-Süss R. Remote loading of doxorubicin into liposomes driven by a transmembrane phosphate gradient. Biochim Biophys Acta. 2006; 1758(10): 1633-1640. [CrossRef]

[29] Sarfraz M, Afzal A, Yang T, Gai Y, Raza SM, Khan MW, Cheng Y, Ma X, Xiang G. Development of dual drug loaded nanosized liposomal formulation by a reengineered ethanolic injection method and its pre-clinical pharmacokinetic studies. Pharmaceutics. 2018; 10(3): 151. [CrossRef]

[30] IB times (2017). India suspends licences of 10 drug firms over product quality, safety issues. Accessed on $25^{\text {th }}$ January, 2020. http://www.ibtimes.co.in/india-suspends-licences-10-drug-firms-over-product-quality-safety-issues-678258 (Accessed on $25^{\text {th }}$ January 2020).

[31] Sainz V, Conniot J, Matos AI, Peres C, Zupanǒiǒ E, Moura L, Silva LC, Florindo HF, Gaspar RS. Regulatory aspects on nanomedicines. Biochem Biophys Res. 2015; 468(3): 504-510. [CrossRef]

[32] Wang JP, Maitani Y, Takayama K, Nagai T. Pharmacokinetics and antitumor effect of doxorubicin carried by stealth and remote loading proliposome. Pharm Res. 2000; 17(7): 782-787. [CrossRef]

[33] Patel NA, Patel NJ, Patel RP. Formulation and evaluation of curcumin gel for topical application. Pharm Dev Technol. 2009; 14(1): 83-92. [CrossRef]

This is an open access article which is publicly available on our journal's website under Institutional Repository at http://dspace.marmara.edu.tr. 